\title{
Differences in the Level of Children Gross Motor Skills Development in Silat, Taekwondo and Karate in Malaysia
}

\author{
Nur Alyaa Athirah Roslan , Borhannudin Abdullah* \\ Department of Sports Studies, Faculty of Educational Studies, University Putra Malaysia, Malaysia
}

Received October 27, 2019; Revised December 2, 2019; Accepted December 24, 2019

Copyright $\odot 2020$ by authors, all rights reserved. Authors agree that this article remains permanently open access under the terms of the Creative Commons Attribution License 4.0 International License

\begin{abstract}
Gross Motor Skills Development plays a very important role in the field of Sports Studies. By constantly and scientifically monitoring their gross motor skills in the sports and recreational activities which they are involved in, such as martial arts, can assure and guide the development of young children motor development. Also, it is important to find out which martial arts would develop more gross motor skills of these children. This study aims to identify the level of development in children gross motor skills who are involved in martial arts sports. These sports consist of Silat, Taekwondo and Karate in Selangor. Methods: This study was an ex-post factor which involving 90 subjects $($ Silat $=30$, Taekwondo $=30$ and Karate $=30$ ) aged from 6 to 10 years and 9 months. The independent variables of the study are the three types of martial arts that the children are practicing in (i.e., Silat, Taekwondo, and Karate). Ulrich's (2000) gross motor development test was adapted in the study to measure the level of children's motor development in martial arts for locomotor and manipulative skills. The obtained raw scores were transcribed to obtain the locomotor standard (SPL) score, manipulative standard score (SPM), locomotor equivalence score (AEL), manipulative age equality score (AEM) and Gross Motor Development Quotient (GMDQ) score (all of which are the dependent variables). The scores were analyzed using ANOVA software to compare children's mean achievement (DV) by martial arts (IV). The findings showed that there was a significant difference in mean AEM scores among martial arts $[\mathrm{F}(2,87)=6.814, \mathrm{p}<.05]$. For Post Hoc Test analysis, there was a significant difference in mean AEM score between Silat and Karate $(\mathrm{p}=.02)$ and between Silat and Taekwondo $(\mathrm{p}=.007)$. There was no mean difference in AEM score between Taekwondo and Karate $(\mathrm{p}=0.99)$. There was no difference between the mean AEL score [F (2, $87)=0.37, \mathrm{p}>.05]$ and the mean GMDQ score $[\mathrm{F}(2,87)=$ $0.034, \mathrm{p}>.05]$ between Silat, Taekwondo and Karate. The
\end{abstract}

findings showed that there is a discrepancy in the development of gross motor in the manipulative skills of children between martial arts sports. According to the findings, it shows that there is a significant increase in motor development for each child according to their sports. However, these developments are not consistent with their chronological age. The GMDQ scores show that the development of children's gross motor skills in martial arts such as Silat, Taekwondo and Karate is still low.

Keywords Gross Motor, Martial Arts, Locomotor Equality, Manipulative Age Equality, GMDQ Score

\section{Introduction}

Motor development is a lifelong cycle (Noramy \& Kamarul Arifin, 2017; Borhanundin \& Kok, 2014; Gallahue \& Ozman, 2006). In particular, motor development is a gradual process whereby individuals perform from simple, irregular and unskilled motor skills to more complex, organized motor skills as they age, (Haywood and Getchell, 2005). However, motor development does not only revolve around age and physical growth. According to Gallahue and Ozman (2006), the development of gross motor also includes various aspects such as physiological systems, motor systems and nervous systems.

Motor development is divided into two parts: gross motor development and fine motor development. Gross motor development is a development of an action that involves one or a large group of muscles that are clearly visible (Lubans, 2010). Fine motor development is a development of an action that involves a small and intangible muscle group (Gallahue, 1998). The development of children's motor skills in the areas of motor 
skills behavior can be seen through the skills of motor skills. The main principle in motor development is the basic motor movement, which is found in the movement using motor skills, (Farrokhi, Zareh, Karimi and Kazemnejad, 2014). Gross motor movement involves a large amount of force exerted by a group of muscles producing a particular movement or skill. These skills refer to the play patterns that are intended and divided into locomotor movements and control of objects (Gallahue, 2006).

Meanwhile, locomotor skills are physical activities that move individuals from one place to another, moving forward, backward or upward, using a variety of skills, (Borhannudin \& Kok 2014). Examples of locomotive skills include walking or running, leaping and skipping. Object control skills are skills that require coordination between the body and objects in terms of sending objects or receiving objects such as hitting and catching (Borhannudin, 2014). Hardy, King, Farrel, Macniven and Howlett (2010) found that early childhood is an important phase in which every change in muscle and motor development occurs very rapidly. The development of children's gross motor skills progresses well when children are able to move around by imitating it (Yasminder Kaur \& Choon Lian, 2018). The mastery of skills will be accelerated in early childhood if they are exposed in advance to the correct use of gross motor skills (Olrich, 2002; Agnes \& Daniel 2009).

The developmental capacity of children's gross motor skills depends on several factors. The factors which affect them are socio-economic status, age, gender and involvement in physical activities such as recreation and sports. The development of gross motor skills for children should develop according to their chronological age. Therefore, this is a key requirement and every educator involved in the syllabus and teaching of physical activities (P.E = Physical Education) should play a major role in ensuring that the children gross motor skills are well developed as they age. According to Borhanuddin and Tan Kien Kok 2014, which quoted a statement from the National Standard of Physical Education (NASPE, 2004) stating that children's motor skills develop through involvement in sports and games. Healthy and active lifestyles during the early stages of childhood will help improve their motor development throughout the growing process. An example of a healthy and active lifestyle for children is to engage them in martial arts activities.

Martial arts is a phrase often used to describe a number of sports which involve physical contact, such as Taekwando, Judo and Karate (Burke, Al-Adawi, Lee and Audette, 2007). The skills found in martial arts include jumping, kicking and punching. These skills are fundamental skills in the development of children's gross motor skills. In addition to encouraging the development of gross motor skills, involvement in martial arts sports also enhances self-confidence, mental and physical strength and makes children more self-reliant (Borhannudin, 2014). From these studies, they propose to conduct a study on other types of martial arts or other sports to determine which sport contributes significantly to the development of children's gross motor skills. Therefore, researchers conducted research on different martial arts in this study. This study attempts to determine whether children's motor skill development is in a good condition after engaging in martial arts and differences in gross motor skills development in Silat, Karate and Taekwondo

The objectives set for this study are to assess the developmental stages of locomotor skills and object control skills (DV), by which the researchers assess: a) locomotor skill age equality scores (AELs), b) object control skill equality scores (AEMs) and assess c) children's Gross Motor Development Quotient (GMDQ) scores children involved in Taekwando, Karate and Silat (IV).

\section{Methods}

\subsection{Design}

The design of this study is structured in the form of ex-post facto because the sample or group was not randomly classified. An ex post facto research design is a method in which groups with qualities that already exist are compared on some dependent variable. Also known as "after the fact" research, an ex post facto design is considered quasi-experimental because the subjects are not randomly assigned - they are grouped based on a particular characteristic or trait. Although differing groups are analyzed and compared in regards to independent and dependent variables it is not a true experiment because it lacks random assignment. The assignment of subjects to different groups is based on whichever variable is of interest to the researchers.

The independent variables of the study are the three types of martial arts that the children are practicing in (i.e., Silat, Taekwondo, and Karate). This study utilized the purposive sampling technique, which is deemed suitable in an ex post facto study research design. The sampling was done on three particular schools in the district of Lembah Klang, Selangor, Malaysia - to which all these three schools offer the three types of martials arts (i.e., Silat, Taekwondo, and Karate) as part of the schools' co-curricular activities. In this study, the samples were classified according to the three types of martial arts and their own characteristics involving 90 subjects ( Silat $=30$, Taekwondo $=30$ and Karate $=30$ ) ranging in age from 6 to 10 years and 9 months. The tests performed are locomotor skills tests and object control tests. The scores were assessed according to 24 criteria of skills in gross motor development by Ulrich (2000). Through this method, researchers can also identify levels of gross motor 
development (DV) in the form of locomotor standard (SPL) scores, manipulative standard scores (SPM), locomotive skill age equilibrium (AEL), manipulative skill age equilibrium (AEM) and Gross Motor Quotient scores (GMDQ) (all of which are the dependent variables). Each locomotive skill and object control skill has its own set of criteria. If the criteria was met, a score of 1 is given, and if not a score of 0 is given. The minimum score is 0 , and maximum score is 48 for each participant. Researchers will analyze video recordings to obtain raw scores. All raw scores were recorded in the provided score form. The video footage obtained from the EOS 550D DSLR camera was transferred to an Acer computer and stored in a folder according to the types of sports.

\subsection{Test Equipment}

The child's level of motor skills and motor abilities in terms of locomotor and object control is used based on the chronological age of each subject. The TGMD-2 instrument measures 12 basic skills and is divided into six locomotor skills and six object control skills. For locomotor skills, each respondent practiced run, gallop, hop, leap, horizontal jump, and slide. For object control skills, the skills tested include striking a stationary ball, stationary dribble, catch, kick, overhand throw, and underhand roll. To perform these gross motor development tests, several types of tools were provided. Among the tools used are (1) 2 sets of Canon EOS 550D DSLR cameras, (2) 1 Accer Aspire V11 Touch computer, (3) cones or scanners to classify each skill test subset, (4) measuring tape, (5) nut., (6) rubber balls, (7) plastic bat, (8) tee batting, (9) basketball, (10) plastic balls, (11) soccer, (12) tennis balls, (13) softball and (14) TGMD-2 personal information form and test score. Test of Gross Motor Development 2 (TGMD-2) with a Cronbach's alpha value of 0.69 for 12 skill tests, 0.46 for locomotor skills and 0.64 for object control skills was used as a testing tool for the selected subject-specific subjects.

\section{Findings}

\subsection{The Developmental Stages of AEL, AEM and GMDQ for Children Involved in Taekwando, Karate and Silat}

Based on the findings, the mean and standard deviation for the overall AEL were $(M=16.17, \mathrm{SP}=6.845)$. For analysis on TAEKWONDO AEL $(\mathrm{M}=16.9, \mathrm{SP}=7.586)$ the highest mean values were obtained, while SILAT $(\mathrm{M}=$ $15.37, \mathrm{SP}=5.816)$ and Karate $(\mathrm{M}=16.23, \mathrm{SP}=7.157)$ is at a lower level. The mean and standard deviation of the overall standard for AEM were $(\mathrm{M}=12.93, \mathrm{SP}=3.865)$. For the analysis on AEL sports $(\mathrm{M}=14.93, \mathrm{SP}=4.719)$ the highest mean values were obtained, while TAEKWONDO $(\mathrm{M}=11.9, \mathrm{SP}=2.139)$ and Karate $(\mathrm{M}=11.97, \mathrm{SP}=3.577)$ is at a lower level. The mean value and overall standard deviation for GMDQ were $(\mathrm{M}=78.6, \mathrm{SP}=10.549)$. For analysis for TAEKWONDO sports AELs $(\mathrm{M}=79.0, \mathrm{SP}=$ 10.151) having the highest mean values, while SILAT sports $(\mathrm{M}=78.3, \mathrm{SP}=10.049)$ and karate $(\mathrm{M}=78.5, \mathrm{SP}=$ 11.714) is placed at a lower level.

Table 1. Descriptive statistics of overall scores for each martial art

\begin{tabular}{cccccc}
\hline Item & Sports & Mean $(\mathrm{M})$ & $\mathrm{N}$ & Standard Deviation (SD) & Descriptive rating \\
\hline AEL & Silat & 15.37 & 30 & 5.816 & Below Average \\
\hline & Karate & 16.23 & 30 & 7.157 & Below Average \\
\hline & Taekwondo & 16.9 & 30 & 7.586 & Below Average \\
\hline Total & 16.17 & 90 & 6.845 & Below Average \\
\hline & & & & Low \\
\hline Silat & 14.93 & 30 & 4.719 & Low \\
\hline Karate & 11.97 & 30 & 3.577 & Low \\
\hline Taekwondo & 11.9 & 30 & 2.139 & Low \\
\hline & Total & 12.93 & 90 & 3.865 & Low \\
\hline & Silat & 78.3 & 30 & 10.049 & 11.714 \\
\hline
\end{tabular}




\subsection{Differences in Locomotor (AEL) Scores for Children Involved in Taekwando, Karate and Silat}

Based on the descriptive analysis in table 1, the mean AEL score for taekwondo is higher than the other two sports. According to table 2, there was no significant difference $F(2,87)=0.373, p>0.05$ between mean AEL scores for Silat, Karate and Taekwondo. As no significant differences were made, group comparative analysis was not required.

Table 2. ANOVA Inference Analysis for AEL

\begin{tabular}{cccccc}
\hline & $\begin{array}{c}\text { Sum of } \\
\text { Squares }\end{array}$ & $\mathrm{df}$ & $\begin{array}{c}\text { Mean } \\
\text { Square }\end{array}$ & $\mathrm{F}$ & Sig. \\
\hline $\begin{array}{c}\text { Between } \\
\text { group }\end{array}$ & 35.467 & 2 & 17.733 & 0.373 & 0.69 \\
$\begin{array}{l}\text { Within } \\
\text { group }\end{array}$ & 4135.033 & 87 & 47.529 & & \\
Total & 4170.5 & 89 & & & \\
\hline
\end{tabular}

\subsection{Are there any Differences in Manipulative Age} (AEM) Scores for Taekwando, Karate and Silat Children?

Based on the descriptive analysis in table 1, the mean AEM score for Silat is higher than the other two sports. According to table 3, there was a significant difference in mean AEM score between Silat, Karate and Taekwondo F $(2,87)=6.814, p<.005$. Due to the significant differences that occur, group comparative analysis should be performed.

Table 3. ANOVA Inference Analysis for AEM

\begin{tabular}{cccccc}
\hline & $\begin{array}{c}\text { Sum of } \\
\text { Squares }\end{array}$ & df & $\begin{array}{c}\text { Mean } \\
\text { Square }\end{array}$ & F & Sig. \\
\hline $\begin{array}{c}\text { Between } \\
\text { group }\end{array}$ & 180.067 & 2 & 90.033 & 6.814 & 0.002 \\
$\begin{array}{l}\text { Within } \\
\text { group }\end{array}$ & 1149.533 & 87 & 13.213 & & \\
Total & 1329.6 & 89 & & & \\
\hline
\end{tabular}

Games-Howell Post Hoc analysis was conducted to see more comparisons between groups. Games-Howell analysis was used for homogeneity test of variance using Levene Statistic to determine significance $(p=0.010)$.

Table 4. Games-Howell Post hoc analysis of AEM scores

\begin{tabular}{ccccc}
\hline (I) sports & (J) sports & $\begin{array}{c}\text { Mean } \\
\text { Difference } \\
(I-J)\end{array}$ & $\begin{array}{c}\text { Std. } \\
\text { Error }\end{array}$ & Sig. \\
\hline \multirow{2}{*}{ Silat } & Karate & $2.967^{*}$ & 1.081 & 0.022 \\
& Taekwondo & $3.033^{*}$ & 0.946 & 0.007 \\
\multirow{2}{*}{ Karate } & Silat & $-2.967^{*}$ & 1.081 & 0.022 \\
& Taekwondo & 0.067 & 0.761 & 0.996 \\
\multirow{2}{*}{ Taekwondo } & Silat & $-3.033^{*}$ & 0.946 & 0.007 \\
& Karate & -0.067 & 0.761 & 0.996 \\
\hline
\end{tabular}

According to Table 4, the AEM scores for the three different martial arts groups indicate that there are significant differences between each item. High mean difference scores occurred between Silat and Taekwondo with a mean of 3.033 and a significant difference value of $p$ $=0.007$ compared to mean difference between Silat and Karate with a mean of 2.967 and a significant difference value of $p=0.022$. Whereas the mean difference between karate and taekwondo was very low at 0.067 and it was found that there was no significant difference in AEM scores between Karate and Taekwondo.

\subsection{Differences in the GMDQ Scores of Taekwando, Karate and Silat}

Based on the descriptive analysis in table 1, the mean GMDQ score for taekwondo was highest compared to the other two sports by value $(\mathrm{M}=79, \mathrm{SP}=10.151)$. According to table 5, there was no significant difference $\mathrm{F}$ $(2,87)=0.03, p>0.05$ for GMDQ scores between Silat, Karate and Taekwondo.

Table 5. Inference analysis of GMDQ scores using Anova test

\begin{tabular}{cccccc}
\hline & $\begin{array}{c}\text { Sum of } \\
\text { Squares }\end{array}$ & df & $\begin{array}{c}\text { Mean } \\
\text { Square }\end{array}$ & F & sig \\
\hline $\begin{array}{c}\text { Between } \\
\text { group }\end{array}$ & 7.8 & 2 & 3.9 & 0.034 & 0.966 \\
$\begin{array}{c}\text { Within } \\
\text { group }\end{array}$ & 9895.8 & 87 & 113.745 & & \\
\hline Total & 9903.6 & 89 & & & \\
\hline
\end{tabular}

\section{Discussion}

Human motor development is an ongoing cycle and it is an increasingly important area of academic study for those studying Physical and Health Education (CBC) and Sports Science. As a natural process in human beings, the development of gross motor skills refers to changes in the ability to move and movement is a basic or general movement as it extends over life (Payne \& Larry, 2012).

Based on a study of the level of motor skill development of 90 children involved in this sport, the findings show that their level of locomotor skill development did not show significant differences. Depending on the mean SPL score, the average mean SPL score was 7.34 (minimum $=1$, maximum $=11)$. For locomotor age $($ AEL $)$, mean score was 16.17. The locomotor skills found in the TGMD-2 test are six of the 12 basic locomotor skills of running, galloping, one-leg jump, long jump, high jump and sideways. Running is a natural movement that develops from walking. According to Whitall and Getchell (1995), on average children begin to show running skills between six months and six months after they are able to work independently. The movement of the running skills will improve with age. Next is the jumping skill. Jumping exercises require children to push their bodies into the air 
with the production of force from the leg muscles. Most kids can do jump skills after they master the skills or are proficient in running

After running and jumping, new movement skills such as galloping and side steps will emerge. This movement is said to be more difficult because it requires coordination throughout the body. However, based on the results of this video recording analysis, most of them could not meet the movement criteria set out in the TGMD-2 test. As an example of running skills, most of them lay flat on the entire foot on the floor and the hand-eye coordination is not working well. This may be because the movement norms of these three types of sports do not require them to do sprinting properly.

In terms of locomotor age (AEL), children in all three sports are still below average. According to Payne (2012), children can practice their skills by meeting all the criteria at the age of six and above. As for stand-up jumping skills, most children in all three sports are unable to meet the set criteria. This is because, at this age of 10 , the leapfrog began to be acquired. On average, some of the criteria for each locomotive skill start at the age of six. Children in martial arts, karate and taekwondo should be above average as the ages selected in this study range from 6 years to 10 years and 9 months. This may be due to a lack of emphasis on proper locomotor skills during training sessions.

In general, once the child is able to move around without help, the hands are free to explore the environment constantly. With the change of time, experience and training, both eye and foot coordination increased dramatically. At this point, children will begin to exhibit categories of skills referred to as manipulative skills or object control. These skills include throwing, catching, kicking the ball, bouncing the ball and hitting deadly objects. Each of these skills was tested in this study. While it is clear that these elements of movement and skills are not available in martial arts, taekwondo and karate, each child should be able to perform well as it is a basic movement in manipulative gross motor skills and is listed in the Gross Motor Development Test, Ulrich (2000). For manipulative motor skill development, children begin to master all the criteria of movement starting at the age of 6 and reaching maximum mastery at 10 years old. However, the development of manipulative skills in boys occurs much earlier than in girls.

Furthermore, with regard to mastery of manipulative skills (SPM), Silat is scaled at a higher level than Taekwondo and Karate. The overall mean value for SPL is 5.47 (minimum $=2$, maximum $=11$ ). This is because Silat has more movement and object control skills than Karate and Taekwondo. For example, in Silat, they will be taught using tools such as wood, keris, cloth and so on. Although these tools are not used all the time, they still have experience using them. This causes Silat to have a higher level of manipulative skills than Karate and Taekwondo sports.

\section{Conclusions}

Engaging in sports at an early age has a lot of positive effects on children. As for gross motor skills development, children are encouraged to participate in various sports at the early age of five or six years. This is supported by Premachandran (2006) on a 4-year-old who set a 65-kilometer track record in seven hours and two minutes. The importance of sports involvement to children is to enhance locomotor and manipulative skills while also enhancing the specific skills of the sport. For example, Silat, Taekwondo and Karate have similar skills such as kicking, jumping, punching and so on. In order to master these specific skills, children must have good mastery of basic motor skills

In addition, during their involvement in sports, children are better able to interact with the environment as described in ecological perspective and dynamic systems theory approach. Good interaction between individuals, the environment and tasks will motivate good motor movement. In addition to enhancing the motor skills, it can also promote social skills, cognitive skills, muscle strength and build a positive attitude and character in children (Borhanuddin, 2014)

\section{Recommendation}

It is best in humanity interest that the results of this study will serve as a guide, a foundation for parents to send their children as young as five to a sports training center in particular so that it can assist the development of children's motorcycle development. This is clear because maturity and experience are fundamental principles in human motor development. In addition, it is best in our interest that schools will make martial arts a major co-curricular club similar to that of football and netball to assist with age-appropriate motor development.

The research conducted by the researcher involved only a small and not comprehensive scope of research. It is suggested that in future studies, researchers increase the number of subjects in motor development activities according to age and comparison of more sports. In addition, further studies need to be conducted on different types of individual or group sports to identify sports that have the most influence on children's motor development.

In addition, the next proposal is to enhance physical activity among school students by making martial arts sports among the major sports clubs in the curriculum. This indirectly enhances social cohesion and promotes a healthy and active body. 


\section{REFERENCES}

[1] Agnes, W. Y. P. \& Daniel, T. P. F. (2009). Fundamental motor skill proficiency of Hong Kong children aged 6-9 years. Research in Sports Medicine, 125-144W.

[2] Borhanuddin, A., \& Kok, T. K. (2014). The Differences of Gross Motor Development Level among Taekwondo Athletes. Journal of Scientific Research, 187-191.

[3] Burke, D. T., Al-Adawi, S. \& Lee, Y. T., \& Audette, J. (2007). Martial arts as sport and therapy. Journal of Sports Medicine and Physical Fitness, 96- 102

[4] Farrokhi, A., Zareh, Z.M., Karimi, A.L., Kazemnejad, A., \& Ilbeigi, S. (2014). Reliability and validity of test of gross motor development-2 (Ulrich, 2000) among 3-10 aged children of Tehran City. Journal of Physical Education and Sport Management, 5(2), 18-28.

[5] Gallahue, D. \& Ozmun, J. C. (1998). Understanding Motor Development. Infants, Children, Adolescent and Adult. New York: McGraw-Hill

[6] Gallahue, D. L. \& Ozmun, J. C. (2006). Understanding motor development: Infants, children, adolescents, adults (6th ed.). New York: McGraw-Hill

[7] Hardy, L. L., King, L., Farrell, L., Macniven, R., \& Howlett, S. (2010). Fundamental movement skills among Australian preschool children. Journal of Science and Medicine in Sport, 13(5), 503-508

[8] Haywood, K. M., \&Getchell, N. (2005). Life Span Motor Development (4th ed,).Champaign: Human Kinetics

[9] Noramy, N. I., \& Kamarul Arifin , S. (2017). Perbezaan Kemahiran Motor Berdasarkan Jantina Dalam Kalangan Kanak-Kanak Pra Sekolah. Jurnal Sains Sosial, 25-35.

[10] Olrich, T. W. (2002). Assessing fundamental motor skills in the elementary school setting: Issues and Solutions. Journal of Physical Education, Recreation \&Dance, 73(7), 26-28

[11] Payne, V. G., \& Larry, D. Isaacs. (2012). Human Motor Development Lifespan Approach. New York: McGraw-Hill.

[12] Whitall, J., \& Getchell, N. (1995). From walking to running: Applying a dynamical systems approach to the development of locomotor skills. Child Development, 66, 1541-1553. 